\title{
Exploring Factors for Achieving Successful Educational Attainment among Chinese Doctoral Students in the United States
}

\author{
Shiyou Wu \\ Qi Wu \\ Arizona State University, USA \\ Xiaojiang Wei \\ Renmin University of China, China \\ Sarah E. Bledsoe \\ David Ansong \\ University of North Carolina at Chapel Hill, USA
}

\begin{abstract}
This study aims to understand the pathways of successful educational attainment (SEA) among Chinese students who are pursuing doctorate degrees in the United States. An exploratory qualitative approach was used to identify the factors of SEA. Based on the in-depth interviews of nine participants, we found common factors of SEA at the micro level include individuals' personalities, visions/dreams of achieving SEA, and interest about study/research; mezzo level factors include important peoples' help, satisfaction with teachers, previous education experiences in China, and home environment; whereas at the macro level, not many participants mentioned that their SEA was due to Chinese social policy. Overall, most participants mentioned that being lucky was an important factor of SEA.
\end{abstract}

Keywords: Chinese doctoral student, Chinese education, education inequity, educational attainment, higher education 


\section{INTRODUCTION}

According to the annual Open Doors report from the Institute of International Education (2019), about 1.1 million international students were enrolled in colleges and universities in the United States during the 2018-2019 academic year. Within this international student cohort, China was the most named country of origin, with 369,548 students $(33.7 \%$ of total international students. A National Science Foundation report (2018) showed that of the 55,195 students awarded doctoral degrees in the United States in 2016, approximately 35\% of those degrees were earned by foreign students $(n=19,185)$. Of those foreign students, about $29 \%$ came from China ( $n=5,534$; including Hong Kong), ranking as the top country for foreign students earning doctorates in the United States.

In China, these doctoral students have been treated as elite students or exceptional intellectual talents (Song, 2003). Among 16,000 chemistry PhD graduates in 161 U.S. universities, Chinese students published more during their studies in the United States than all other students in the same field, controlling for the characteristics of the programs they were enrolled in (Gaule \& Piacentini, 2013). Roughly $87 \%$ of Chinese doctoral students planned to stay in the United States after graduating from $\mathrm{PhD}$ programs (National Science Foundation, 2017). Johnson (2010) concluded that Chinese doctoral students provide critical contributions to the development of science and technology, as well as the global competitiveness of the United States. As well, these students have created significant economic benefits through increased levels of industrial and business innovation (Kellogg, 2010).

Educational attainment can be defined as "the highest grade or degree completed" (Child Trends, 2018). This study explores pathways to successful educational attainment (SEA) in students who have achieved the highest level of education (i.e., a doctoral degree). Specifically, this study focuses on Chinese doctoral students actively engaged in graduate level study at a public Research 1 university in the southeastern United States.

To date, there is limited research that explores Chinese doctoral students' pathways to achieve high SEA. Previous studies of this population have not identified factors that lead these Chinese students to study at the doctoral level in the United States. To address this research gap, and to understand pathways to SEA in the unique developmental and environmental context of China, we used an exploratory qualitative approach to identify factors facilitating high SEA among Chinese students pursuing doctorate degrees in the United States.

\section{Theoretical Framework}

This study used an ecosystems perspective to identify factors for achieving high SEA among Chinese doctoral students. The ecosystems perspective, which originated in biology and is rooted in ecology (Dubos, 1972), as well as general systems theory (von Bertalanffy, 1967), can be used to understand interconnectedness between people and their physical and social environments (Germain, 1979; Gitterman \& Germain, 2008). Ecosystem levels can be separated into three types of systems: 
micro, mezzo, and macro systems (Zastrow \& Kirst-Ashman, 2007). In this study, a micro system is the smallest system unit, i.e., the individual; mezzo system refers to family, peer group, school, and other small groups; while a macro system refers to systems larger than small groups, such as community, society, culture, and social policy. Based on these three levels of the ecosystems perspective, this study studied the factors facilitating high SEA in Chinese social environmental contexts.

\section{Chinese Education System}

In the mid-1980s, following the first of the Opening Up economic reforms, the Chinese government instituted educational reforms to meet the demand for an educated workforce and to improve quality of life. These changes spawned a series of ongoing reforms aimed at increasing equality in educational opportunities. In 1986, China implemented a nationwide educational policy providing all children with nine years of compulsory education. The aim of this policy was to ensure that all children had access to six years of primary education (Grades 1-6) and three years of junior high school education (Grades 7-9).

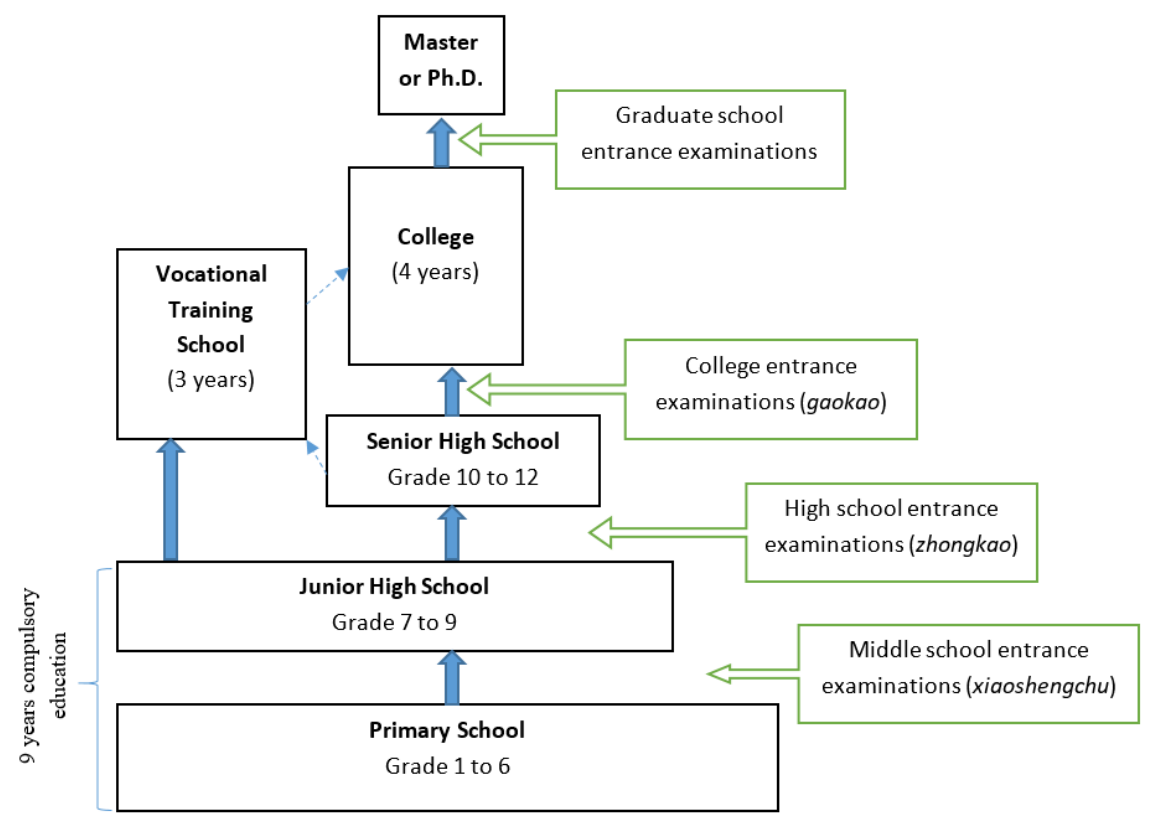

Figure 1: Education System in China

After the 9-year compulsory education (i.e., Grades 1 thru 9; see Figure 1), students must pass a standardized examination (zhongkao) to be admitted to senior high school (Grades 10-12). Once a student passes the exam, their performance is 
evaluated to determine whether they will attend an academic senior high school or a vocational school. The Chinese education system is a test-based educational system, which requires all students pass the higher level education entrance qualifying examinations (e.g., zhongkao or gaokao) at the end of each study period. Therefore, students must achieve a passing score to enroll in the next higher level of education. In addition, secondary education in China is not free, which causes many students who failed the entrance examination to choose not to pursue education beyond Grade 9 .

\section{Educational Context in China}

In 1979, the Chinese government implemented a Reform and Opening Up initiative that began a series of sweeping policy changes aimed at improving China's economy by establishing trade with other nations. Despite the Opening Up economic reforms and the nation-wide free education policy, disparities in educational outcomes continue to exist in China. Specifically, China's quest for universal education has been threatened by differences in the quality of public education across regions and the socioeconomic strata. For example, a substantial gap exists in the quality of education offered in rural versus urban environments. These differences stem from unequal government financial investment/expenditures for school facilities and teacher salaries. These differences, in turn, affect other factors that influence educational outcomes, including the quality of teaching, teacher-student ratios, class sizes, classroom equipment, and quality of school facilities. Rural schools receive less funding and are unable to match the quality of education offered in urban schools (Huang, 2009; C. Wu, 2007). Differences in funding can lead to a cascade of negative social, economic, and political challenges. Differential treatment by the central government threatens the educational success of children living in rural areas who lack access to quality education. Not only do these threats have a negative impact on child development, but they also adversely affect the political and economic future of China. For example, one consequence of the unequal quality of education in rural and urban schools is a substantial difference in the percentage of students who pass their qualifying exams (e.g., zhongkao or gaokao). A crucial benchmark, passing the entrance qualifying examinations, allows students to continue their education.

\section{Educational Attainment Disparity}

Recent research conducted in developing countries indicate students from lowincome families often have low educational attainment (Brown \& Park, 2002; Filmer, 2000), and China is no exception. Compared with their urban counterparts, many students from poor, rural areas of China have lower educational attainment, poorer outcomes in areas such as math and English, and lower rates of transitioning to higher education levels (i.e., low school enrollment from primary to junior high school and from junior high to high school; Brown \& Park, 2002; Connelly \& Zheng, 2003; Chen et al., 2013). Moreover, several studies show that students from low socioeconomic status households are less likely to attend college (Li et al., 2015). For example, Li et al. (2015) used a $1 \%$ random sample of the 2000 census data from China and found 
that compared with urban students, students from low-income households in rural areas were seven times less likely to attend any college classes and 11 times less likely to attend top-ranking universities. This evidence indicates a large educational attainment gap between rural and urban students, and among different socioeconomic statuses in China.

\section{Predictors of Educational Attainment}

The existing literature on educational attainment in the United States indicates that household assets are strong predictors of child educational outcomes such as college attendance (Elliott, 2008; Zhan \& Sherraden, 2011), expectation of college education (Ansong, Wu \& Chowa, 2015), academic achievement (e.g., math and reading scores; Orr, 2003; Zhan \& Sherraden, 2003), and children's college completion (Conley, 2001; Nam \& Huang, 2009). For example, research demonstrates children from high-income families are more likely to achieve a higher academic performance than children from economically disadvantaged families (Conley, 2001). Research also examines the relationship between home environment and children's outcome (including educational outcomes), and suggests that parents' active investment in the physical environment and supportive materials may affect children's outcomes (Totsika \& Sylva, 2004). In addition, parents' nurturing and monitoring time may also impact their children's school performance (Becker, 1993). Moreover, parents' and children's educational expectations, children's self-esteem, and children's attitudes and behaviors are also important predictors in determining educational outcomes (Elliott et al., 2010; Shanks et al., 2010).

In spite of the large number of Chinese doctoral students studying in the United States, there is a paucity of literature exploring the factors facilitating high SEA. The current study was guided by the following research question: What are the factors that facilitate the high educational achievement of Chinese doctoral students in the United States? To answer this question, we conducted qualitative individual interviews with Chinese doctoral students to (a) explore their paths for achieving high SEA, and (b) identify common factors that facilitated high SEA in a Chinese context.

\section{METHOD}

All methods and procedures used in this study were approved by the Institutional Review Board at the University of North Carolina at Chapel Hill.

\section{Sample and Sampling Strategy}

We recruited a sample of nine Chinese doctoral students from a public Research 1 university in the southeastern United States. As noted by Sandelowski (1995), sample size in qualitative research should not be so small that it is difficult to achieve data saturation, theoretical saturation, or informational redundancy. At the same time, the sample should not be so large that it is difficult to undertake a deep, case-oriented analysis. In this study, we used a convenience sample and recruited until data saturation was achieved. 


\section{Inclusion Criteria}

This study was limited to students who went through the Chinese educational system and immigrated to the United States for the purpose of university study at the doctoral level. To be eligible for study inclusion, individuals had to meet all of the following criteria: (a) the participant came from China to the United States to pursue a doctoral degree; (b) the participant studied from primary school to college in China and already had a bachelor's (or master's) degree from a college or university in China prior to coming to the United States; (c) the participant was currently enrolled and pursuing a doctoral degree in the United States; and (d) the participant can speak both English and Chinese. Only participants who met all of these four criteria were recruited in this study.

\section{Exclusion Criteria}

Anyone who was not Chinese was excluded, as this study was focused on the educational attainment of Chinese doctoral students and producing strategies to help other vulnerable groups (e.g., low-income families or migrant families) improve educational attainment within the Chinese educational system.

\section{Recruitment Strategy}

To identify participants, the first author (PI) invited Chinese doctoral students to participate in the study. This was done in person based on the PI's social network and with the help of the university's Fraternity Association of Chinese Students and Scholars (FACSS) community. FACSS is the largest Chinese student organization at this University, and many Chinese doctoral students are members of FACSS.

The PI began recruitment by inviting doctoral students he already knew through his membership in FACSS. The first author then used convenience and snowball sampling to identify nine Chinese doctoral students. At the end of each interview, participants were asked to recommend any other Chinese doctoral students at the university for this study. Email addresses were collected (or identified using the person search engine on the university homepage) and the students were sent an email inviting them to participate in the study.

\section{Data Collection}

This study used qualitative, face-to-face, in-depth interviews to identify and describe the participants' pathways for achieving SEA. At the beginning of each individual interview, the PI reviewed the informed consent form with participants to ensure potential participants understood the purpose, basic premise, risks and benefits of this research, and the protective procedures to ensure confidentiality and safety. All participants were informed that they were voluntary participants who had the right to decline to participate, the right to withdraw from the study at any time, and had the right to refuse to respond to any questions at any time. The PI also encouraged each participant not to provide any identifying information during the interview, and 
informed the participant that any identifying information would be replaced with generic identifiers in the transcripts (e.g., S1, S2 ... S9).

After providing informed consent, participants were asked to complete a demographic questionnaire prior to the interview. To collect data, a semistructured and in-depth interview format was utilized for all interviews. The standard set of questions included: (a) "Tell me what you experienced in China that makes you come to the United States for PhD study?"; (b) "Are there any other factors that helped you to achieve SEA?"; and (c) "Could you tell me more about your education experience in China, both good and bad, that may have impacted your current academic achievement?" Based on individual responses, the interviewer posed follow-up questions to probe for greater detail or to clarify the meaning of participants' responses. Eight interviews were audiotaped with participant consent. One participant declined audiotaping. For this participant, data were collected by taking notes. After interviewing, the interviewer wrote down the important information based on notes and memory. The interviews lasted about 1 hour, and all participants were interviewed just once.

\section{Data Analyses}

All recordings of interviews were transcribed verbatim. All the transcripts or interview notes were sent back to the interviewees and were confirmed as accurate by the interviewees. The research team developed an initial list of codes for the transcripts, and based on the a priori code list, an open-coding approach (Padgett, 2016) was independently conducted by two coders. All inconsistent codes were discussed in the team to ensure the accuracy and consistency of the emergent codes. We continued coding and analyzing the transcripts until saturation of the data was obtained (e.g., no new categorizations or themes identified), and a cluster of common themes emerged as key findings ( $\mathrm{S}$. Wu et al., 2016). Data was managed using ATLAS.ti 7.0 (Scientific Software Development GmbH, Berlin, Germany). Based on these findings, the team employed thematic coding to summarize the similarities and differences of the factors that were identified as facilitating high SEA in the study sample.

\section{RESULTS}

\section{Demographic Descriptions}

This study utilized a questionnaire to obtain participants' demographic information. Table 1 summarizes this information. The total sample size was nine, with six female and three male participants. Most of the participants were between 26 and 30 years old $(66.67 \%)$. Seven participants were married. Three participants were first-year doctoral students, two were second-year, and four were third-year doctoral students. Four participants were in science disciplines, and five of them belonged to liberal arts disciplines. All of them received a full scholarship (tuition fee, stipend, health insurance, financial support, etc.). In terms of their family background, only one of the participants' fathers had a bachelor's degree; five of their fathers had an 
associate's degree (including professional training degree or postsecondary degree); one of their fathers graduated from high school; and two of their fathers studied up to the primary school level. Three of the participants' mothers had associate degrees, four graduated from high school, and two studied at a primary school level. In this sample, five participants came from one-child families, three participants had one sibling, and one had four siblings. Five families' average annual incomes were 10,000 to 50,000 yuan ( $\$ 1 \approx ¥ 7$ ), two in the range of $¥ 50,000$ to $¥ 100,000$, one in the range of $¥ 100,000$ to $¥ 200,000$, and one family’s income was more than 200,000 yuan.

Table 1: Demographic Descriptions of Participants

\begin{tabular}{|c|c|c|}
\hline Characteristics & $\begin{array}{c}\text { Number of } \\
\text { respondents } \\
(N=9)\end{array}$ & $\%$ \\
\hline \multicolumn{3}{|l|}{ Gender } \\
\hline Male & 6 & 66.67 \\
\hline Female & 3 & 33.33 \\
\hline \multicolumn{3}{|l|}{ Age } \\
\hline $21-25$ & 1 & 11.11 \\
\hline $26-30$ & 6 & 66.67 \\
\hline $31-40$ & 2 & 22.22 \\
\hline \multicolumn{3}{|l|}{ Married } \\
\hline Yes & 7 & 77.78 \\
\hline No & 2 & 22.22 \\
\hline \multicolumn{3}{|l|}{ Years in the United States } \\
\hline 1 & 1 & 11.11 \\
\hline 2 & 2 & 22.22 \\
\hline 3 & 6 & 66.67 \\
\hline \multicolumn{3}{|l|}{ Years in $\mathrm{PhD}$ program } \\
\hline 1 & 3 & 33.33 \\
\hline 2 & 2 & 22.22 \\
\hline 3 & 4 & 44.44 \\
\hline \multicolumn{3}{|c|}{ Same major of bachelor and $\mathrm{PhD}$} \\
\hline Yes & 6 & 66.67 \\
\hline No & 3 & 33.33 \\
\hline \multicolumn{3}{|l|}{ Type of university, bachelor } \\
\hline Key university & 7 & 77.78 \\
\hline Second-level university & 2 & 22.22 \\
\hline \multicolumn{3}{|c|}{ Same major of master's and $\mathrm{PhD}$} \\
\hline Yes & 8 & 88.89 \\
\hline No & 1 & 11.11 \\
\hline \multicolumn{3}{|l|}{ Type of university, master } \\
\hline Key university & 5 & 55.56 \\
\hline Second-level university & 1 & 11.11 \\
\hline Others (in United States) & 3 & 33.33 \\
\hline Discipline of PhD & & \\
\hline
\end{tabular}




\begin{tabular}{lcc}
\hline & $\begin{array}{c}\text { Number of } \\
\text { respondents } \\
(N=9)\end{array}$ & $\%$ \\
\hline Characteristics & 4 & 44.44 \\
\hline Sciences & 5 & 55.56 \\
Liberal arts & 0 & 0 \\
Engineering & & \\
Full scholarship & 9 & 100 \\
Yes & & \\
No & & \\
Father’s educational level & 2 & 22.22 \\
Primary school & 1 & 11.11 \\
High school & 5 & 55.56 \\
Associate’s degree & 1 & 11.11 \\
Bachelor's degree & & \\
Mother’s educational level & 2 & 22.22 \\
Primary school & 4 & 44.44 \\
High school & 3 & 33.33 \\
Associate’s degree & & \\
Number of siblings & 5 & 55.56 \\
0 & 3 & 33.33 \\
1 & 1 & 11.11 \\
4 & & \\
Family annual income $(\$ 1 \approx ¥ 6.2)$ & 5 & 55.56 \\
$¥ 10,000 \sim 50,000$ & 2 & 22.22 \\
$¥ 50,000 \sim 100,000$ & 1 & 11.11 \\
$¥ 100,000 \sim 200,000$ & 1 & 11.11 \\
$¥>200,000$ & & \\
\hline
\end{tabular}

\section{Self-Perceived Reasons for SEA}

Analysis of the nine interview transcripts using open coding strategies in ATLAS.ti 7.0 resulted in several themes concerning pathways for achieving SEA. A codebook (see Appendix A) was also generated, mainly utilizing the ecosystems perspective. Participants' self-perceived reasons for achieving SEA were organized into three levels: micro, mezzo, and macro. In order to present more details, this study also created four subcode clusters, including personalities, important persons, previous education experiences, and home environment, as a summary of the same cluster information.

\section{Micro Systems}

\section{Personality}

The code cluster of personality was often first mentioned when a participant gave reasons for SEA, and all nine participants indicated that their personalities were a key factor in SEA. Although different participants had different personalities (see Table 
2), we observed common characteristics that associated with SEA. For example, all participants agreed that their persistence helped them to achieve SEA. S7 said, "Once I have a plan, I will try my best to persist on the plan until finished or success. For example, since primary school, I will not go outside for fun until I finished all the homework." S4 shared the following:

I have a dream since I was a primary student that one day I can study in the best university of China. However, because I failed in the college entrance examination, so I want to make it for my master study. The first time I participated the national postgraduate entrance examination, I failed, and then I spent another year to prepare the second examination, unfortunately, I failed again. I was almost going to give up, but my dream came out again. So, I told myself: life is short, I have to do something that I really want to do. Therefore, I persist to take the third time of the national postgraduate entrance examination, and finally I got success after three years!

Besides persistence, diligence was also a common factor for SEA. Eight participants mentioned that they worked very hard for their success - for example, S5 said, "I almost don't have leisure time in my high school, studying was the only thing of my life." S4 disclosed that "I am not a smart person, so I have to study very hard, even much harder than my classmates." S6 was the only one who said she felt she was not studying very hard:

I feel that I can easily understand and remember the knowledge, and I feel that I don't need to spend too much time on study, and I can still be the best student in my school. So, honestly, compared to other students, I am not a diligent student.... which my classmates always 'hate' me...

However, the perception of being smart (i.e., being gifted students) was not a common factor, as only two participants thought their success was because of being smart. The most common factors for achieving SEA included: possessing organizational skills, being competitive, having a high level of intellect, demonstrating self-control, and having an easy-going disposition.

\section{Having a SEA Vision/Dream}

In addition to personality, all of the participants said that they had a vision or dream about SEA. For example, S9 said: "My mother always descripted and repeat me a vision about future life that once I study very hard, and get admitted by a good university, and then I will have a very good life in the future!" And S1 said, "I have an America dream. My major in undergraduate was English Literature, so I always wanted to come to the United States" S3 mentioned that:

I have a cousin. She is 10 years older than me, and she came to the US first, so my father wants me to follow her. He often told to me that I have to study the English very well so that in the future I can go to the US for my future study like my cousin. He encouraged me to think about preparing to go to the US and pushing me to achieve this goal since I was a college student. 
Although some of their visions or dreams were advocated by others such as parents, relatives, or teachers, these visions or dreams played a direct or indirect role in encouraging participants to achieve SEA.

In analyzing the transcripts, we determined that the other most common factors in achieving SEA at the individual level included: being good at finding resources, taking advantage of opportunities as they present themselves, and possessing the desire to be a good student.

\section{Table 2: Summary of Reasons for Successful Educational Attainment at the} Micro Level

\begin{tabular}{|c|c|c|c|c|c|c|c|c|c|c|}
\hline Codes and code families & S1 & $\mathrm{S} 2$ & S3 & S4 & S5 & S6 & S7 & S8 & S9 & Sum \\
\hline 1. Personality & $\sqrt{ }$ & $\sqrt{ }$ & $\sqrt{ }$ & $\sqrt{ }$ & $\sqrt{ }$ & $\sqrt{ }$ & $\sqrt{ }$ & $\sqrt{ }$ & $\sqrt{ }$ & 9 \\
\hline Persistence & $\sqrt{ }$ & $\sqrt{ }$ & $\sqrt{ }$ & $\sqrt{ }$ & $\sqrt{ }$ & $\sqrt{ }$ & $\sqrt{ }$ & $\sqrt{ }$ & $\sqrt{ }$ & 9 \\
\hline Diligence & $\sqrt{ }$ & $\sqrt{ }$ & $\sqrt{ }$ & $\sqrt{ }$ & $\sqrt{ }$ & & $\sqrt{ }$ & $\sqrt{ }$ & $\sqrt{ }$ & 8 \\
\hline Organized & & $\sqrt{ }$ & $\sqrt{ }$ & $\sqrt{ }$ & $\sqrt{ }$ & $\sqrt{ }$ & $\sqrt{ }$ & $\sqrt{ }$ & $\sqrt{ }$ & 8 \\
\hline Competitive & $\sqrt{ }$ & & $\sqrt{ }$ & $\sqrt{ }$ & $\sqrt{ }$ & & $\sqrt{ }$ & $\sqrt{ }$ & $\sqrt{ }$ & 7 \\
\hline Self-control & $\sqrt{ }$ & $\sqrt{ }$ & & $\sqrt{ }$ & $\sqrt{ }$ & & $\sqrt{ }$ & $\sqrt{ }$ & $\sqrt{ }$ & 7 \\
\hline Intellect & & $\sqrt{ }$ & $\sqrt{ }$ & & $\sqrt{ }$ & $\sqrt{ }$ & $\sqrt{ }$ & $\sqrt{ }$ & $\sqrt{ }$ & 7 \\
\hline $\begin{array}{l}\text { Easygoing/ } \\
\text { communicative }\end{array}$ & $\sqrt{ }$ & & $\sqrt{ }$ & & $\sqrt{ }$ & $\sqrt{ }$ & $\sqrt{ }$ & & $\sqrt{ }$ & 6 \\
\hline Compassionate/ simple & $\sqrt{ }$ & $\sqrt{ }$ & $\sqrt{ }$ & & & $\sqrt{ }$ & $\sqrt{ }$ & & & 5 \\
\hline Timid & $\sqrt{ }$ & & & & $\sqrt{ }$ & $\sqrt{ }$ & $\sqrt{ }$ & & & 4 \\
\hline Confidence & & $\sqrt{ }$ & $\sqrt{ }$ & & $\sqrt{ }$ & & $\sqrt{ }$ & & & 4 \\
\hline Independent & & & & & & & $\sqrt{ }$ & $\sqrt{ }$ & $\sqrt{ }$ & 3 \\
\hline Very smart/gifted & & & & & & $\sqrt{ }$ & $\sqrt{ }$ & & & 2 \\
\hline Truthful & $\sqrt{ }$ & & & & & & & $\sqrt{ }$ & & 2 \\
\hline Passionate & $\sqrt{ }$ & & & $\sqrt{ }$ & & & & & & 2 \\
\hline Optimistic & & & $\sqrt{ }$ & & & & & & & 1 \\
\hline Righteous & & & & & & & & $\sqrt{ }$ & & 1 \\
\hline Sum & 9 & 7 & 9 & 6 & 9 & 7 & 12 & 9 & 8 & 76 \\
\hline $\begin{array}{l}\text { 2. Have a vision/ } \\
\text { dream/ plan/model }\end{array}$ & $\sqrt{ }$ & $\sqrt{ }$ & $\sqrt{ }$ & $\sqrt{ }$ & $\sqrt{ }$ & $\sqrt{ }$ & $\sqrt{ }$ & $\sqrt{ }$ & $\sqrt{ }$ & 9 \\
\hline $\begin{array}{l}\text { 3. Interested in study/ } \\
\text { research }\end{array}$ & & $\sqrt{ }$ & & $\sqrt{ }$ & $\sqrt{ }$ & $\sqrt{ }$ & $\sqrt{ }$ & $\sqrt{ }$ & $\sqrt{ }$ & 7 \\
\hline $\begin{array}{l}\text { 4. Good at finding } \\
\text { resources }\end{array}$ & & & $\sqrt{ }$ & $\sqrt{ }$ & $\sqrt{ }$ & $\sqrt{ }$ & & $\sqrt{ }$ & $\sqrt{ }$ & 6 \\
\hline $\begin{array}{l}\text { 5. Good earlier } \\
\text { education foundation }\end{array}$ & $\sqrt{ }$ & & $\sqrt{ }$ & & $\sqrt{ }$ & $\sqrt{ }$ & $\sqrt{ }$ & & & 5 \\
\hline 6. Being a good student & $\sqrt{ }$ & & $\sqrt{ }$ & $\sqrt{ }$ & $\sqrt{ }$ & & & & $\sqrt{ }$ & 5 \\
\hline $\begin{array}{l}\text { 7. Good at finding } \\
\text { opportunities }\end{array}$ & & & $\sqrt{ }$ & & $\sqrt{ }$ & $\sqrt{ }$ & & $\sqrt{ }$ & $\sqrt{ }$ & 5 \\
\hline $\begin{array}{l}\text { 8. Balance for all } \\
\text { disciplines }\end{array}$ & $\sqrt{ }$ & & $\sqrt{ }$ & & $\sqrt{ }$ & & $\sqrt{ }$ & & & 4 \\
\hline 9. Good at study & & $\sqrt{ }$ & $\sqrt{ }$ & & & & $\sqrt{ }$ & & & 3 \\
\hline
\end{tabular}




\begin{tabular}{llllllllllc}
\hline Codes and code families & S1 & S2 & S3 & S4 & S5 & S6 & S7 & S8 & S9 & Sum \\
\hline $\begin{array}{l}\text { 10. Good language } \\
\text { ability }\end{array}$ & $\sqrt{ }$ & & $\sqrt{ }$ & & & & & & & 2 \\
$\begin{array}{l}\text { 11. Alternate study with } \\
\text { rest }\end{array}$ & $\sqrt{ }$ & & $\sqrt{ }$ & & & & & & & 2 \\
\hline
\end{tabular}

Note. $\mathrm{S}=$ subject; $\mathrm{S} 1-\mathrm{S} 6$ are female; $\mathrm{S} 7-\mathrm{S} 9$ are male.

\section{Mezzo Systems}

As shown in Table 3, three code clusters were the most common reasons for SEA at the mezzo level: participants had some help from important people, previous education experiences, and home environment.

\section{Having Help From an Important Person}

Teachers and peer groups, such as friends and classmates, were the common important people mentioned by all nine participants. As S7 said:

My advisor [master degree's] suggested me to come to the US for my $\mathrm{PhD}$, and helped me to connect my current boss [PhD supervisor] here and recommended me to him, without my advisor's help, I would not be able to come here.

S8 believed that his Chinese class teacher in high school changed his life:

Before I met that teacher, I was not a good student. I addicted to watch novels, and many of my courses were not so good, and no one expected me to success in the college entrance examination. However, I was good at writing, maybe because I read a lot of novels, my Chinese class teacher like my writings and often treated my writing as an example to my classmates. He knew my situation, and asked me to come to his office, and talk with me for a long time. He encouraged me, and said I am a smart student, with great potential to be a good student, and definitely will be success in the future, something like that. Anyway, his words suddenly waked me up, and I never read novels since then. I start to study very very hard, and I succeed! I got admitted in a college, although it was not the best one, for me, it was good enough!

The nine participants also mentioned that their friends and classmates contributed to their SEA by providing emotional support, tutoring classes, and consulting in career planning. Of the seven married participants, five of them believed they were impacted by their spouse. For those who had siblings, three participants said their SEA was related to their siblings. Mothers had the highest impact on participants' SEA. In this study, S1 to S6 were female, S7 to S9 were male. As indicated in Table 3 , only female students were affected by fathers, while none of the male participants described being affected by their father. 


\section{Previous Education Experiences}

Previous education included preschool, primary school, middle school, high school, undergraduate, and master's study experiences. We found that all nine participants consistently believed that high school experiences were the most important. Master, undergraduate, and primary school study experiences were also identified as common important factors in achieving SEA (see Table 3). However, only S7 believed that the middle school experience was important to achieving SEA because:

I studied primary school and middle school in a small village. It is a small school, we only have about 50 students in each year, so the competition was not very serious, and I can easily to be the best students in my school. After I finished middle school study, I was selected to study in the best high school of our county because I was the top one student in my middle school.

Other participants indicated that middle school experience was not important to their current SEA. For example, S8 said:

I was not a good student before high school, but not too bad, I mean, I knew the basic things. And you know, things studied in primary school and middle school were not too much and not too hard. It was possible for us to catch up if we study hard. However, high school learnt much more things than before, more participants, and much more harder, if we lose too much, it is not easy to catch up. I was lucky that I start to study hard at the end of the first semester in high school.

S2, S3, and S9 shared S8's perspective on the middle school experience. They saw middle school as a transition period, and even though they were not the best students there, they still succeeded in the college entrance examination by studying very hard during the high school period.

\section{A Supportive Home Environment}

Having a supportive family, experiencing a good family economic situation, parenting, and tutoring were all important contributing factors in achieving SEA (see Table 3). Having a supportive family means that the participants' parents often encouraged and praised them when they were young. In addition, being supportive also meant offering financial support. S5 said: "My parents unconditionally support me when I need to buy study materials. Once I wanted to take any interest classes such as piano, and dancing. They also supported me." S1 also said: "I have a good family environment, they are supportive to me, and I don't have to worry about working for my family, or making money, so I don't have to work at a young age." S5 described her family environment and parental support as:

I think I have grown up in a family where my parents both worked. Because they had a relatively good work, so they had extra time to take care of my assignment. I remember my father did a lot when I was in primary school, 
and that helped a lot. Many other students in my school, they just, yeah, if they missed something, they didn't catch up this month, then next month they would be getting worse. My father tutored me all through the primary school. But for middle school, he cannot do that anymore...haha! But I already got a very good foundation, and that helps a lot. So I can go to a good middle school.

Table 3: Summary of Reasons for Successful Educational Attainment at Mezzo Level

\begin{tabular}{|c|c|c|c|c|c|c|c|c|c|c|}
\hline Codes/code families & $\mathrm{S} 1$ & $\mathrm{~S} 2$ & S3 & S4 & S5 & S6 & S7 & S8 & S9 & Sum \\
\hline 1. Important person & $\sqrt{ }$ & $\sqrt{ }$ & $\sqrt{ }$ & $\sqrt{ }$ & $\sqrt{ }$ & $\sqrt{ }$ & $\sqrt{ }$ & $\sqrt{ }$ & $\sqrt{ }$ & 9 \\
\hline Teacher & $\sqrt{ }$ & $\sqrt{ }$ & $\sqrt{ }$ & $\sqrt{ }$ & $\sqrt{ }$ & $\sqrt{ }$ & $\sqrt{ }$ & $\sqrt{ }$ & $\sqrt{1}$ & 9 \\
\hline $\begin{array}{l}\text { Peers/ friends/ } \\
\text { classmates }\end{array}$ & $\sqrt{ }$ & $\sqrt{ }$ & $\sqrt{ }$ & $\sqrt{ }$ & $\sqrt{ }$ & $\sqrt{ }$ & $\sqrt{ }$ & $\sqrt{ }$ & $\sqrt{ }$ & 9 \\
\hline Mother & $\sqrt{ }$ & $\sqrt{ }$ & $\sqrt{ }$ & $\sqrt{ }$ & & & & $\sqrt{ }$ & $\sqrt{ }$ & 6 \\
\hline Spouse/boyfriend & & $\sqrt{ }$ & $\sqrt{ }$ & $\sqrt{ }$ & & $\sqrt{ }$ & $\sqrt{ }$ & & $\sqrt{ }$ & 6 \\
\hline Father & & & $\sqrt{ }$ & $\sqrt{ }$ & $\sqrt{ }$ & $\sqrt{ }$ & & & & 4 \\
\hline Relatives/ neighbors & & $\sqrt{ }$ & $\sqrt{ }$ & & $\sqrt{ }$ & & & $\sqrt{ }$ & & 4 \\
\hline Siblings & & & & $\sqrt{ }$ & & $\sqrt{ }$ & & & $\sqrt{ }$ & 3 \\
\hline Sum & 3 & 5 & 6 & 6 & 4 & 5 & 3 & 4 & 5 & 41 \\
\hline $\begin{array}{l}\text { 2. Previous educational } \\
\text { experience }\end{array}$ & $\sqrt{ }$ & $\sqrt{ }$ & $\sqrt{ }$ & $\sqrt{ }$ & $\sqrt{ }$ & $\sqrt{ }$ & $\sqrt{ }$ & $\sqrt{ }$ & $\sqrt{ }$ & 9 \\
\hline Preschool & & & $\sqrt{ }$ & & $\sqrt{ }$ & & & & & 2 \\
\hline Primary school & $\sqrt{ }$ & $\sqrt{ }$ & & $\sqrt{ }$ & $\sqrt{ }$ & & $\sqrt{ }$ & & $\sqrt{ }$ & 6 \\
\hline Middle school & & & & & & & $\sqrt{ }$ & & & 1 \\
\hline High school & $\sqrt{ }$ & $\sqrt{ }$ & $\sqrt{ }$ & $\sqrt{ }$ & $\sqrt{ }$ & $\sqrt{ }$ & $\sqrt{ }$ & $\sqrt{ }$ & $\sqrt{ }$ & 9 \\
\hline Undergraduate study & $\sqrt{ }$ & $\sqrt{ }$ & $\sqrt{ }$ & & $\sqrt{ }$ & $\sqrt{ }$ & & $\sqrt{ }$ & $\sqrt{ }$ & 7 \\
\hline Master's study & $\sqrt{ }$ & $\sqrt{ }$ & $\sqrt{ }$ & $\sqrt{ }$ & $\sqrt{ }$ & & $\sqrt{ }$ & $\sqrt{ }$ & $\sqrt{ }$ & 8 \\
\hline Sum & 4 & 4 & 4 & 3 & 5 & 2 & 4 & 3 & 4 & 33 \\
\hline 3. Home environment & $\sqrt{ }$ & $\sqrt{ }$ & $\sqrt{ }$ & $\sqrt{ }$ & $\sqrt{ }$ & $\sqrt{ }$ & & $\sqrt{ }$ & $\sqrt{ }$ & 8 \\
\hline Supportive family & $\sqrt{ }$ & $\sqrt{ }$ & $\sqrt{ }$ & $\sqrt{ }$ & $\sqrt{ }$ & $\sqrt{ }$ & $\sqrt{ }$ & $\sqrt{ }$ & $\sqrt{ }$ & 9 \\
\hline $\begin{array}{l}\text { Good family } \\
\text { economic situation }\end{array}$ & $\sqrt{ }$ & $\sqrt{ }$ & $\sqrt{ }$ & $\sqrt{ }$ & $\sqrt{ }$ & $\sqrt{ }$ & & $\sqrt{ }$ & $\sqrt{ }$ & 8 \\
\hline Parenting & $\sqrt{ }$ & $\sqrt{ }$ & $\sqrt{ }$ & $\sqrt{ }$ & $\sqrt{ }$ & $\sqrt{ }$ & & & $\sqrt{ }$ & 7 \\
\hline Tutoring & $\sqrt{ }$ & $\sqrt{ }$ & $\sqrt{ }$ & $\sqrt{ }$ & $\sqrt{ }$ & & & & $\sqrt{ }$ & 6 \\
\hline Sum & 4 & 4 & 4 & 4 & 4 & 3 & 1 & 2 & 4 & 30 \\
\hline 4. Satisfied by teacher & & $\sqrt{ }$ & $\sqrt{ }$ & & $\sqrt{ }$ & $\sqrt{ }$ & $\sqrt{ }$ & $\sqrt{ }$ & $\sqrt{ }$ & 7 \\
\hline $\begin{array}{l}\text { 5. Previous experiences } \\
\text { in China }\end{array}$ & $\sqrt{ }$ & $\sqrt{ }$ & $\sqrt{ }$ & $\sqrt{ }$ & & & & $\sqrt{ }$ & $\sqrt{ }$ & 6 \\
\hline $\begin{array}{l}\text { 6. Best education } \\
\text { condition }\end{array}$ & $\sqrt{ }$ & & & & $\sqrt{ }$ & & & & & 2 \\
\hline
\end{tabular}

Note. $\mathrm{S}=$ subject; $\mathrm{S} 1-\mathrm{S} 6$ are female; $\mathrm{S} 7-\mathrm{S} 9$ are male. 


\section{Geographic Location of Previous Education}

We also collected information regarding the geographic location of participants' previous education. As shown in Figure 2, primary school was same location as where the participants grew up, and then, starting in middle school, rural areas became less common, as more participants went to a suburban or an urban area for study. S7 and S9 indicated that cities had better education qualities than rural areas. All participants went to capital cities (of each province), including four who studied in Beijing, the capital city of China, for their higher education. None of them stayed in the small cities, town or suburban areas, or rural areas.

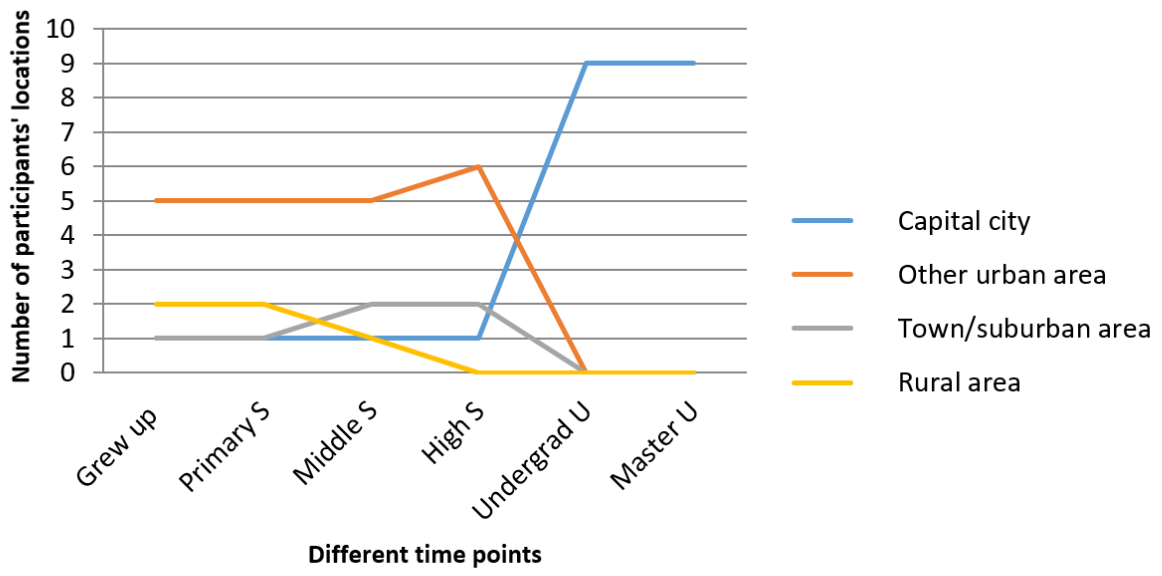

Figure 2: Distribution of Geographic Locations of Participants

The data showed that at the mezzo level, in addition to the previously indicated three code clusters, there were other common factors that helped them to achieve SEA: teacher satisfaction during their previous study, and their previous working, internship, volunteer, or research experiences in China.

\section{Macro Systems}

At the macro level, few participants identified macro factors that facilitated high SEA. Instead, several participants said that Chinese social policy played an adverse role in their SEA. Without the barriers created by social policy or society level, participants believed that they could have achieved SEA earlier or more easily. For example, S2 mentioned that: "In 2003, the year I took the college entrance examination, the government closed all the schools because of SARS [Severe Acute Respiratory Syndrome], without that, I may do a better job in the college entrance examination." In addition, S3 indicated that Chinese culture is biased against women; she said: 
My growing up environment told me that girl is not as smart as boy. Even in the university, my master advisor also held the similar opinion, and thought the boy's hands are more flexible than girls, and therefore, boy is more suited to be a doctor. So whatever we [as females] tried our best to do something, we cannot to be as good as the boy did.

However, a good community environment was given as a reason for achieving SEA. Five of the participants mentioned that their community was good, and their neighbors were relatively educated (see Table 4). Therefore, in their community, their peers learned good aspects from each other. Moreover, they had access to better education equipment, and more and better social education resources, which contributed positively in helping them achieve SEA.

\section{Luck Contributes to SEA}

Seven participants could not discount luck in playing a role in their achieving SEA (Table 4). S3 was one who did not take luck into account because she had strong self-confidence, and everything in her life was planned, organized, and perceived as under her control. S7 also did not believe luck played an important role for him. He said, "I study very hard, and I always did a good job on study [he was also the one who claimed to be a smart person], so I don't think my success was because of lucky. I believe the old saying: no pains, no gains!"

Table 4: Summary of Reasons for Successful Educational Attainment at the Macro Level and Other Comment Factors

\begin{tabular}{lcccccccccc}
\hline Codes & S1 & S2 & S3 & S4 & S5 & S6 & S7 & S8 & S9 & Sum \\
\hline $\begin{array}{l}\text { Macro level } \\
\quad \text { Good community }\end{array}$ & & $\sqrt{ }$ & $\sqrt{ }$ & & $\sqrt{ }$ & $\sqrt{ }$ & & $\sqrt{ }$ & & 5 \\
$\quad \begin{array}{l}\text { environment } \\
\quad \text { Social network }\end{array}$ & & & & & & & & & & \\
$\quad$ Social policy/society & & & & $\sqrt{ }$ & & $\sqrt{ }$ & & $\sqrt{ }$ & $\sqrt{ }$ & 4 \\
\hline Sum & 0 & 1 & 1 & 2 & 1 & 3 & 0 & 2 & 2 & 12 \\
\hline Others & & & & & & & & & & \\
$\quad$ Lucky & $\sqrt{ }$ & $\sqrt{ }$ & & $\sqrt{ }$ & $\sqrt{ }$ & $\sqrt{ }$ & & $\sqrt{ }$ & $\sqrt{ }$ & 7 \\
\hline
\end{tabular}

Note. $\mathrm{S}=$ subject; $\mathrm{S} 1-\mathrm{S} 6$ are female; $\mathrm{S} 7-\mathrm{S} 9$ are male.

\section{DISCUSSION}

This qualitative study interviewed nine Chinese doctoral students from a public Research 1 university in the southeastern United States. Participants' self-perceived reasons for achieving high SEA were summarized into three levels: micro, mezzo, and macro. At the micro level, the reasons shared by more than six participants were: individuals' personalities, interest in study/research, having a vision/dream to achieve SEA, previous educational experiences in China, skill at finding resources, and taking advantage of opportunities were the most common factors in achieving SEA. At the 
mezzo level, having the help of an important person, teacher satisfaction, previous education experiences in China, and home environment were the most common reasons given for participants' achievement of SEA. At the macro level, not many participants indicated that their SEA benefited from Chinese social policy or other macro level factors. Besides these three levels, most participants agreed that luck was an important factor facilitating their achieving SEA.

These identified common factors of students who achieved SEA in the Chinese social context have important implications for Chinese educators. In addition, this study can provide a reference for dealing with the low educational success population groups in China, such as migrant populations, those from rural areas, and some western provinces. Knowing the factors for achieving SEA, we can now compare the situations of these high SEA students with lower SEA population groups. If lower SEA is due to lack of factors shown to facilitate achieving high SEA, tailored interventions and new policies can be developed to help encourage the creation of those missing factors.

At the micro level, some of the natural personalities were not replicable, such as intelligence. However, personality traits such as the common factors of persistence, diligence, organization, and self-control can be nurtured. Therefore, intervention for building up positive personalities in lower SEA groups may improve the likelihood of achieving high SEA. In addition, developing mentoring programs to help groups with lower SEA to have a dream or vision about obtaining higher SEA may improve outcomes. For example, pairing college students with lower SEA with tutors may not only improve their studies, but also set up a good model, thereby giving lower SEA groups a higher education dream or vision. Many students with lower SEA have very limited educational resources due to lack of information and access to public resources. Thus, we can also connect students with lower SEA to public resources such as education resources, financial aid foundations, and volunteer resources.

At the mezzo level, the impact of peer groups was very important for achieving a high SEA. Creating peer groups can provide good peer experiences for groups with lower SEA, and can guide their studies. Furthermore, study results indicated the importance of encouragement from teachers at all levels of education. At the family level, many students with lower SEA come from single parent families, migrant families, or left-behind families, wherein the parents are busy with work, and often lack time to tutor their children (Shi, 2002). Therefore, there is a need for services that provide after-school care that includes a safe and supportive environment for students, where they can receive tutoring to help them achieve their educational attainments.

At the macro level, this study found that high school experiences were a common factor in achieving SEA. However, many students with lower SEA (e.g., migrant children, left-behind children) did not have equal opportunities to study at high schools in cities, or even dropped out after graduating from middle school (Shi, 2002; $\mathrm{S}$. Wu, 2010; S. Wu \& Wu, 2013) because of the current hukou policy. These policies force students from underdeveloped areas to remain or return to their hometown for higher education. However, as we can see from Figure 2, all the participants moved to cities for their higher education, which is the common pathway of achieving SEA based on the experiences of these nine participants. Therefore, we can advocate for 
the Chinese government to change the current policies, and to give equal rights and opportunities to every child obtaining higher education.

Several limitations of this study should be addressed. First, the sample size was small and convenience sampling was used. Although this study sample was recruited until data saturation was achieved, the sample was from only one public university; thus successful students who studied in private universities may have been excluded. Second, this study only used international students as examples, so we may also exclude students who stayed in China for their $\mathrm{PhD}$ studies. Therefore, we may have missed some other important factors of achieving SEA, and the sample was not representative of all students who achieved high SEA in a Chinese context. Third, achieving SEA is sometimes related to factors that did not replicate to another's experience. Because each student is a unique individual, students will experience a different contexts, pathways, reasons, and styles toward achieving SEA. These limitations affect the generalizability of the study findings, as well as restrict the extension of its implications. Nevertheless, this study provides an in-depth understanding of the factors of SEA at the micro, mezzo, and macro levels. The identification of factors for achieving a high SEA not only contributes to the literature of Chinese higher education, but also provides significant implications for helping the lower SEA groups in China. For future studies, we would suggest developing a larger survey sample size specifically focused on SEA groups. Additionally, including some of the research questions in the current national survey questionnaire may help capture the common factors in achieving a higher SEA based on a national representative sample.

\section{REFERENCES}

Ansong, D., Wu, S., \& Chowa, G. A. (2015). The role of child and parent savings in promoting expectations for university education among middle school students in Ghana: A propensity score analysis. Children and Youth Services Review, 58, 265-273.

Becker, G. S. (1993). Human capital: A theoretical and empirical analysis, with special reference to education. University of Chicago Press.

Brown, P. H., \& Park, A. (2002). Education and poverty in rural China. Economics of Education Review, 21, 523-541.

Chen, X., Shi, Y., Mo, D., Chu, J., Loyalka, P., \& Rozelle, S. (2013). Impact of a senior high school tuition relief program on poor junior high school students in rural China. China \& World Economy, 21(3), 80-97.

Child Trends. (2018). Educational attainment. Retrieved March 29, 2020 from www.childtrends.org/?indicators=educational-attainment

Conley, D. (2001). Capital for college: Parental assets and postsecondary schooling. Sociology of Education, 74, 59-72.

Connelly, R., \& Zheng, Z. (2003). Determinants of school enrollment and completion of 10 to 18 year olds in China. Economics of Education Review, 22(4), 379-388.

Dubos, R. (1972). The God within. Charles Scribner's Sons. 
Elliott, W. (2008). Closing the gap in college enrollment: The potential of children's college accounts (CSD Working Paper 08-16). Washington University, Center for Social Development.

Elliott, W., Jung, H., \& Friedline, T. (2010). Math achievement and children's savings: Implications for child development accounts. Journal of Family and Economic Issues, 31, 171-184.

Filmer, D. (2000). The structure of social disparities in education. World Bank Policy Research Working Paper No. 2268.

Gaule, P., \& Piacentini, M. (2013). Chinese graduate students and US scientific productivity. Review of Economics and Statistics, 95, 698-701.

Germain, C. B. (1979). Introduction: Ecology and social work. In C. B. Germain (Ed.), Social work practice: People and environments (pp. 1-22). Columbia University Press.

Gitterman, A., \& Germain, C. B. (2008). Ecological framework. Encyclopedia of Social Work, 20, 97-102.

Huang, J. (2009). Education resource allocation imbalance and its impact on social justice. Theory and Contemporary, 5, 29-32.

Institute of International Education. (2017). Open doors 2019. Retrieved March 29, 2020 from https://www.iie.org/en/Research-and-Insights/Open-Doors/OpenDoors-2019-Media-Information

Johnson, J. (2010). Human resource contributions to U.S. science and engineering from China. Issue Brief, Division of Science Resources Studies of National Science Foundation.

Kellogg, R. (2010, February 18). Chinese $S \& E$ graduate students in the US: The increasing lure of the economic boom back home? [Paper presentation]. International Studies Association 51st Annual Conference, New Orleans, LA, United States.

Li, H., Loyalka, P., Rozelle, S., Wu, B., \& Xie, J. (2015). Unequal access to college in China: How far have poor, rural students been left behind?. The China Quarterly, 221, 185-207.

Nam, Y., \& Huang, J. (2009). Equal opportunity for all? Parental economic resources and children's educational attainment. Children and Children Services Review, $31,625-634$.

National Science Foundation. (2016). National Center for Science and Engineering Statistics, survey of earned doctorates. https://www.nsf.gov/statistics/2018/nsf18304/data.cfm

National Science Foundation. (2017). Doctorate recipients from U.S. universities: 2015. Special Report NSF 17-306. https://www.nsf.gov/statistics/2017/nsf17306

Orr, A. (2003). Black-white differences in achievement: The importance of wealth. Sociology of Education, 76, 281-304.

Padgett, D. K. (2016). Qualitative methods in social work research (Vol. 36). Sage.

Sandelowski, M. (1995). Sample size in qualitative research. Research in Nursing \& Health, 18, 179-183.

Shanks W., T. R., Kim, Y., Loke, V., \& Destin, M. (2010). Assets and child wellbeing in developed countries. Children and Youth Services Review, 32, $1488-1496$. 
Shi, B. (2002). Urban migrant children education policy analysis. Journal of China Youth University for Political Sciences, 21, 31-35.

Song, W. (2003). U.S. Chinese doctoral students' flows and employment. Beijing Observation, 10, 36-38.

Totsika, V., \& Sylva, K. (2004). The home observation for measurement of the environment revisited. Child and Adolescent Mental Health, 9, 25-35.

von Bertalanffy, L. (1967). General systems theory. In N. Demerath \& R. A. Peterson (Eds.), Systems change and conflict (pp. 119-129). Free Press.

$\mathrm{Wu}, \mathrm{C}$. (2007). Research of the evolution process and influence factors on the gap between urban and rural compulsory education financial funds. Education Science, 23, 1-5.

$\mathrm{Wu}, \mathrm{S}$. (2010). Education and class reproduction of migrant children. China Youth Study, 174(8), 61-65.

Wu, S., \& Wu, Q. (2013). Migrant youths in Beijing: A life history analysis of class reproduction. China Journal of Social Work, 6(1), 52-68.

Wu, S., Wyant, D. C., \& Fraser, M. W. (2016). Author guidelines for manuscripts reporting on qualitative research. Journal of the Society for Social Work and Research, 7(2), 405-425.

Zastrow, C., \& Kirst-Ashman, K. K. (2007). Understanding human behavior and the social environment. Thomson.

Zhan, M., \& Sherraden, M. (2003). Assets, expectations, and children's educational achievement in female-headed households. Social Service Review, 77, 191-211.

Zhan, M. \& Sherraden, M. (2011). Assets and liabilities, race/ethnicity, and children's college education. Children and Youth Services Review, 3, 2168-2175.

SHIYOU WU, MSW, PhD, is an Assistant Professor in the School of Social Work at Arizona State University. His major research interests lie in the area of social determinants of health and create interventions to improve health for impoverished populations nationally and internationally. Email: shiyou.wu@asu.edu

QI WU, PhD, is an Assistant Professor in the School of Social Work at Arizona State University. Her research examines protective factors in youth development and child welfare including kinship diversion, caregivers, and the impacts of welfare participation. Email: qi.wu.5@asu.edu

XIAOJIANG WEI (Corresponding Author), MSW, PhD, is an Associate Professor in the School of Sociology and Population Studies, Renmin University of China. His research focuses on Chinese social problems and social development issues. Email: weixiaojiangyy@163.com

SARAH BLEDSOE, MSW, PhD, is an Associate Professor in the School of Social Work, University of North Carolina at Chapel Hill. Her research focuses on mental health services research, evidence based practice and interpersonal psychotherapy. Email: bledsoe@email.unc.edu 
DAVID ANSONG, MSW, PhD, is an Associate Professor in the School of Social Work, University of North Carolina at Chapel Hill. His research focuses on identifying interventions to address economic and educational disparities among lowincome youth and families in resource-limited countries. Email: ansong@email.unc.edu 